\title{
AN APPARENT ONE-YEAR LAG RELATIONSHIP OF HEAVY SNOW YEARS BETWEEN EURASIA AND NORTH AMERICA
}

\author{
by
}

Tomohiko Iwasaki

(Department of Geophysics, Faculty of Science, Kyoto University, Kyoto 606, Japan)

\section{ABSTRACT}

The purpose of this study is to investigate the interannual variability of winter snow cover in the northern hemisphere, using the satellite-derived monthly snow cover data (NOAA/NESDIS) from 1967 to 1987. An empirical orthogonal function (EOF) analysis is made to see the typical pattern of snow cover variations during winter. EOF1, which represents about $40 \%$ of the total variance, shows concurrent snow cover patterns between Eurasia and North America. EOF2, which represents over $20 \%$ of the total variance, shows a negatively correlated pattern between the eastern and western parts of the continent in Eurasia and North America.

We examined time series of mean snow cover for key regions of the northern hemisphere to investigate variations depicted in the EOF patterns in more detail. We selected two key regions which represent continental-scale snow variation. One is the eastern part of Eurasia and the other is the western part of North America. The time series of the two key regions show an apparent one-year lag relationship of heavy snow cover years; winters with extensive snow cover over Eurasia tend to be followed by extensive snow cover over North America during the succeeding winters.

\section{DATA}

Snow cover extents have been digitized into an $89 \times 89$ grid matrix covering the northern hemisphere using the satellite-derived operational NOAA/NESDIS northern hemisphere weekly snow and ice charts which have been available since November 1966.

There are some limitations in using snow cover data mainly because of cloudiness and resolution in preparing snow charts. Recently, Wiesnet and others (1987) discussed the problems of the data and concluded that the accuracy of the derived digitized data is sufficiently high in winter and in spring for large-scale climate-related studies. Additional details of the accuracy and availability of the data sets are given by Barry (1986) and Robock and Scialdone (1986).

\section{RESULTS}

To investigate characteristic features of snow variation during winter, we performed an EOF analysis for the snow cover data. Data of the original $89 \times 89$ grid matrix were converted into an $8 \times 8$ grid matrix for the northern hemisphere, because the original higher resolution is not necessary to investigate the subcontinental-scale feature of snow cover variations.

Figure 1 is the first component of the EOF (EOF1), which represents about $40 \%$ of the total variance. This shows concurrent snow cover patterns between Eurasia and North America. The score of the EOF1 is similar to the time series of the winter snow cover in the northern hemisphere (cf. Matson and Wiesnet, 1981). The score also shows a negative correlation with summer monsoon total

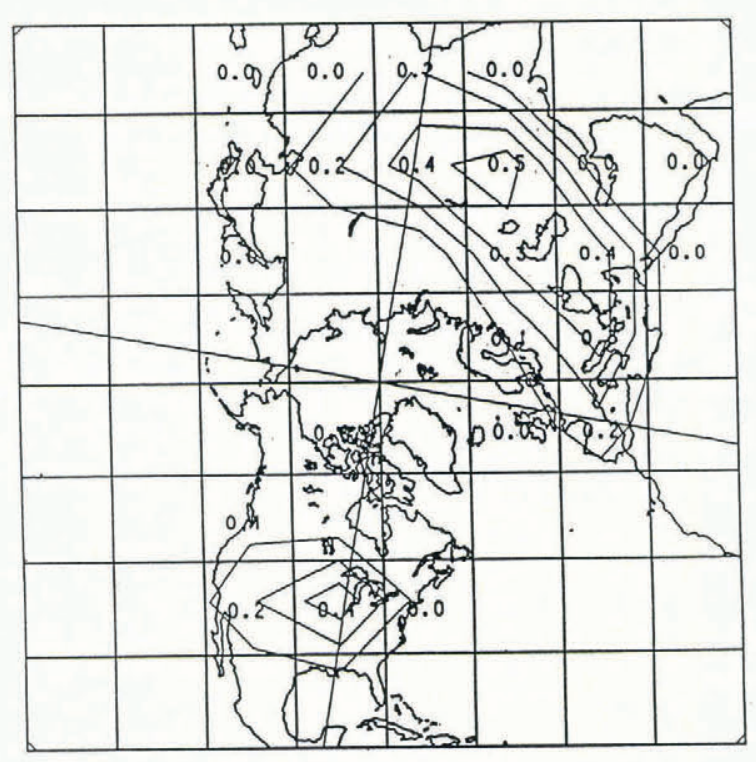

$\left(\mathrm{Km}^{2}\right)$
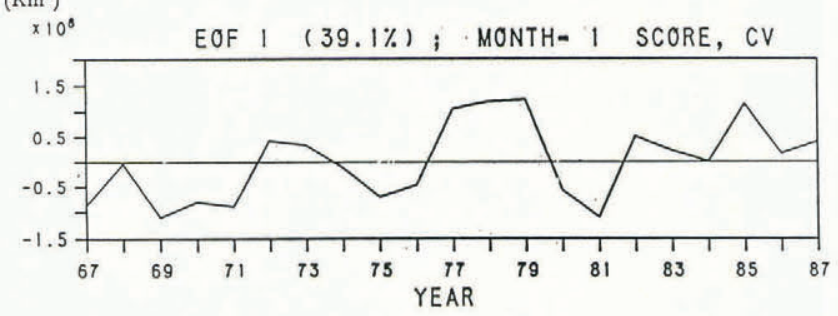

Fig. 1. (Upper): the first component of the EOF for January; (lower): score of the EOF1.

rainfall over India (after Hahn and Shukla, 1976; Dickson, 1984). Yasunari (1987) suggested that the Indian summer monsoon plays an important role in connecting oceanic and land processes leading to El Niño events. Therefore, snow cover fluctuations with an interannual time-scale may be related to the El Niño and Southern Oscillation (ENSO) cycle.

Figure 2 is the second component of the EOF (EOF2), which represents over $20 \%$ of the total variance. This shows a negatively correlated pattern of snow cover between the eastern and western parts of the continent in Eurasia and North America. The EOF2 pattern indicates the importance of subcontinental-scale variations. This pattern is dominant during northern winter months (November-April).

Next we examined the time series of mean snow cover for the representative areas depicted in the EOF patterns to investigate the persistence of snow cover during winter in more detail. Here we show an investigation only for the negatively correlated pattern between the eastern and 


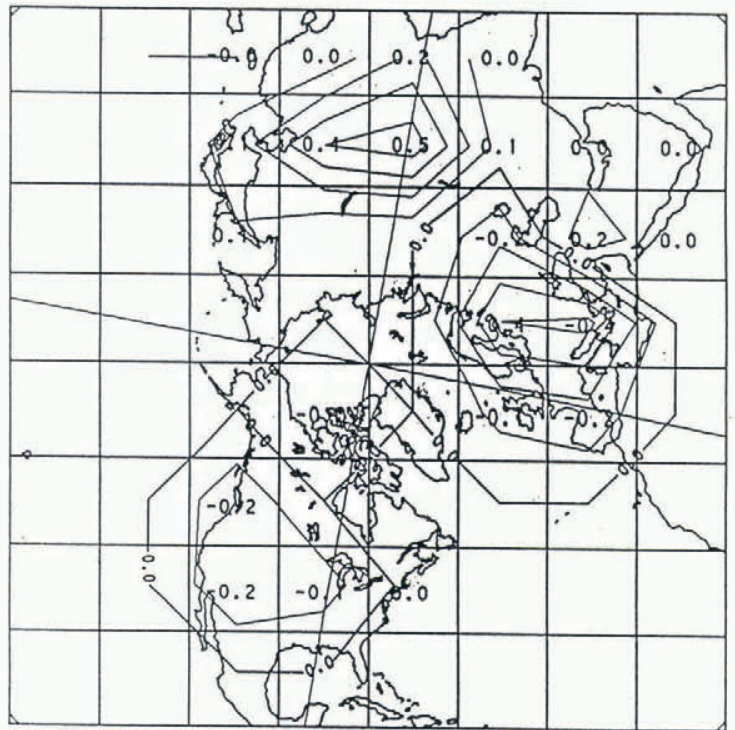

$\left(\mathrm{Km}^{2}\right)$
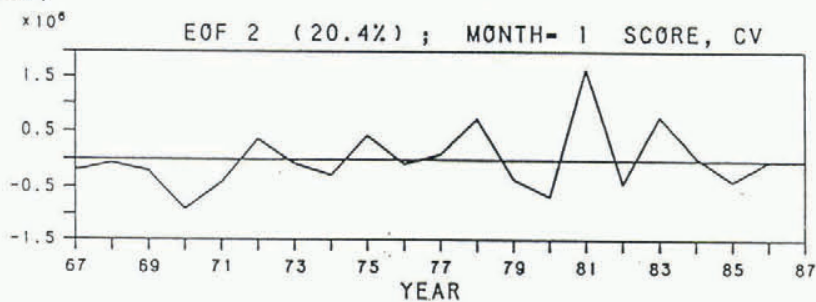

Fig. 2. As in Fig. 1, but for the EOF2.

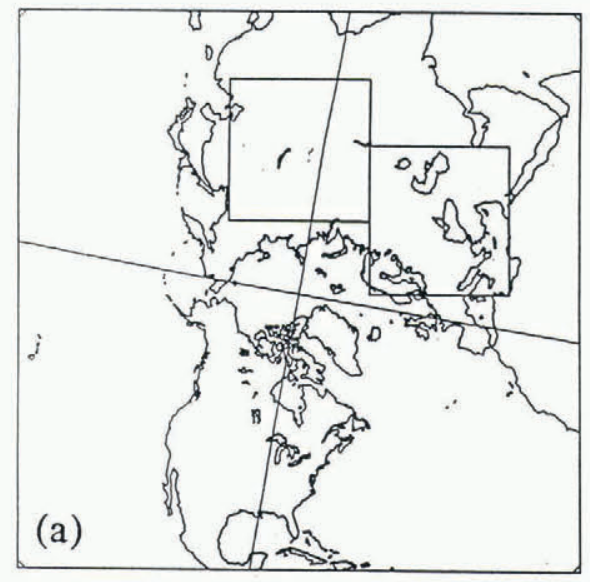

$\left(\mathrm{Km}^{2}\right)$ SNOW COVER SQ Time-Series

\section{$\times 10^{\circ}$ E.EURASIA, MONTH $=$ Dec. - Mar.}

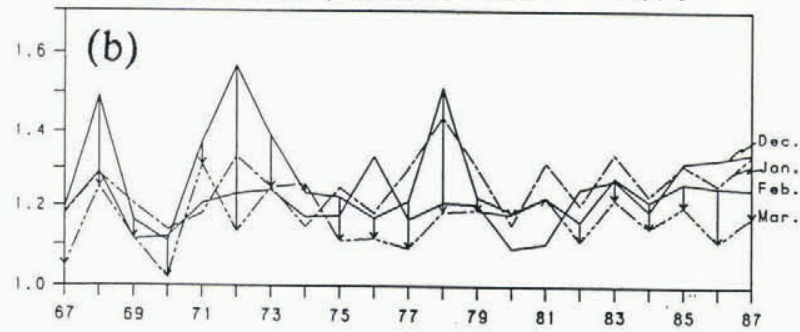

$\left(\mathrm{Km}^{2}\right)$ SNOW COVER SQ Time-Series

$\times 10^{7}$ W.EURASIA, MONTH- Dec. - Mar.

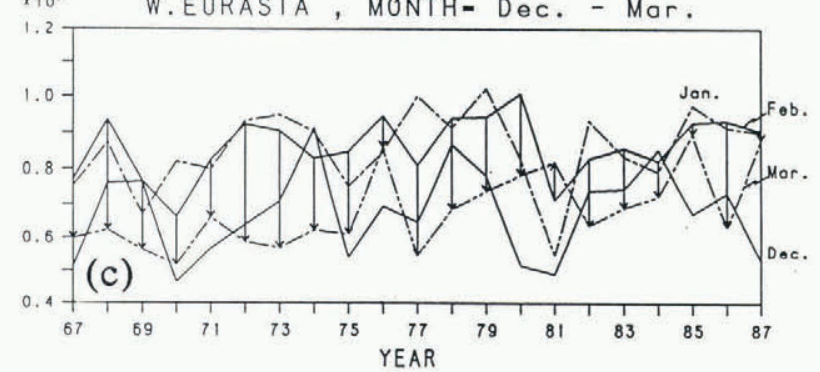

western parts of Eurasia (EOF2). Figure 3(a) shows the representative areas of the EOF2. Figure $3(\mathrm{~b}$ and $\mathrm{c})$ is the time series of the east and west Eurasian mean snow cover from December to March, respectively. Arrows on the figure indicate a decrease in snow cover area from February to March. Generally, significant snow-falls begin in December and the snow-covered area increases until February. In March, snow begins to melt and the snow-covered area decreases rapidly. Heavy snow years which have an extreme extent of total snow cover during winter (December-February) experience more rapid melting in March than any other years, especially in east Eurasia (see the arrows on Fig. 3(b)). This feature is more prominent in eastern than in western Eurasia (cf. Fig. 3(c)). Consequently, snow cover features for a specific year (e.g. a heavy or light snow year) are likely to be sustained during December-February and disappear in March. Eastern Eurasia represents the features of continental-scale and year-to-year snow variations for the Eurasian continent.

From the intraseasonal persistence check for the representative areas, we selected two key regions which represent continental-scale snow variation, eastern Eurasia
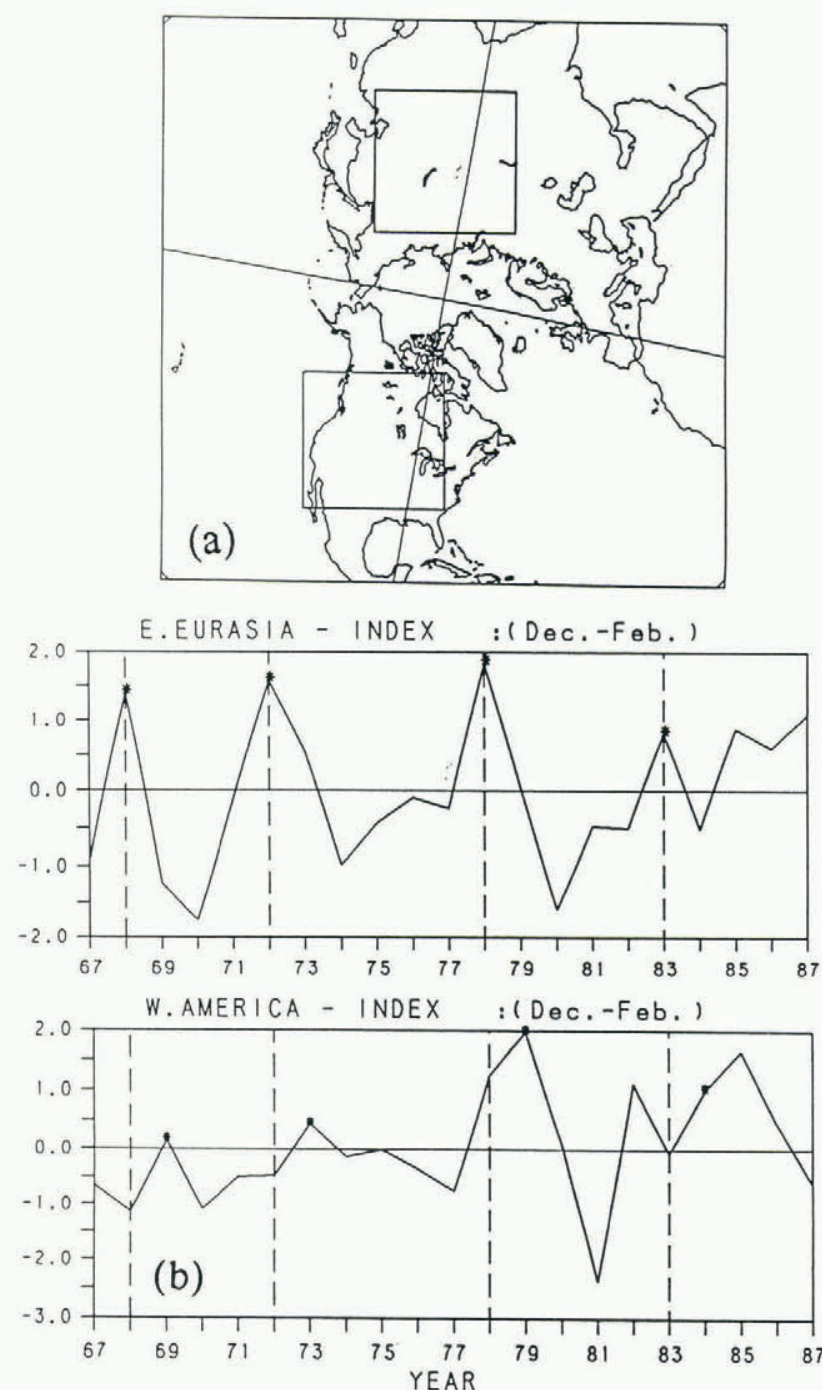

Fig. 4.(a) The two selected key regions which represent continental-scale snow variations. (b) The normalized time series of mean snow cover for the key regions during December-February. The asterisk ${ }^{(*)}$ indicates a heavy snow year for each continent during the data period.

Fig. 3.(a) The representative areas (eastern and western Eurasia) for the EOF2. (b) Time series of the east Eurasian mean snow cover $\left(\mathrm{km}^{2}\right)$ from December to March. (c) Same for west Eurasia. For further detail see text. 
and western North America (see Fig. 4(a)). Fig. 4(b) shows the normalized time series of mean snow cover for these two key regions during northern winter (DecemberFebruary). It is noteworthy that the time series shows an apparent one-year lag relationship of heavy snow cover years between Eurasia and North America. The one-year lag correlation coefficient $(r)$ is 0.55 . This observation has not been previously revealed by analyzing continental snow cover data. Thus an important question arises for future studies: what is the mechanism (summertime memory mechanism) for the one-year lag relationship of heavy snow cover years between the two continents?

\section{FURTHER PROBLEMS}

The analysis for this problem is currently made using atmospheric and oceanic long-term global data sets. Monthly Pacific sea surface temperature (SST) data from NOAA (not shown here) also show a one-year lag in accordance with the east Eurasian snow cover time series. This suggests that Pacific SST may be linked to variations in Eurasian snow cover, and presents an essential clue for future studies.

\section{REFERENCES}

Barry, R.G. 1986. Snow cover data: status and future prospects. In Kukla, G., R.G. Barry, A.D. Hecht, and
D.R. Wiesnet, eds. Snow Watch '85. Boulder, CO, University of Colorado. Cooperative Institute for Research in Environmental Sciences. World Data Center A for Glaciology, 127-139. (Glaciological Data. Report GD-18.)

Dickson, R.R. 1984. Eurasian snow cover versus Indian monsoon rainfall - an extension of the Hahn-Shukla results. J. Climate Appl. Meteorol., 23(1), 171-173.

Hahn, D.G. and J. Shukla. 1976. An apparent relationship between snow cover and Indian monsoon rainfall. $J$. Atmos. Sci., 33, 246-262.

Matson, M. and D.R. Wiesnet. 1981. New data base for climate studies. Nature, 289, 451-456.

Robock, A. and J. Scialdone. 1986. Comparison of Northern Hemisphere snow cover data sets. In Kukla, G., R.G. Barry, A.D. Hecht, and D.R. Wiesnet, eds. Snow Watch '85. Boulder, CO, University of Colorado. Cooperative Institute for Research in Environmental Sciences. World Data Center A for Glaciology, 141-161. (Glaciological Data. Report GD-18.)

Wiesnet, D.R., C.F. Ropelewski, G.J. Kukla, and D.A. Robinson. 1987. A discussion of the accuracy of NOAA satellite-derived global seasonal snow cover measurements. International Association of Hydrological Sciences Publication 166 (Symposium at Vancouver 1987 - Large Scale Effects of Seasonal Snow Cover), 291-304.

Yasunari, T. 1987. Global structure of the El Niño/Southern Oscillation. Part II. Time evolution. J. Meteorol. Soc. Japan, 65, 81-102. 